\title{
Presacral Space
}

National Cancer Institute

\section{Source}

National Cancer Institute. Presacral Space. NCI Thesaurus. Code C132414.

The potential body space formed between the rectum and the sacrum. 